\title{
Velocidade de Propagação de Trinca por Fadiga de Soldas Subaquáticas Molhadas: Avaliação Fora da Água
}

\author{
Ariel Rodríguez Arias ${ }^{1}$, Alexandre Queiroz Bracarense ${ }^{1}$ \\ 1 Departamento de Engenharia Mecânica, Universidade Federal de Minas Gerais - UFMG, Belo Horizonte, MG, Brasil.
}

Recebido: 21 Set., 2015

Aceito: 26 Nov., 2015

E-mails: arielra2506@gmail.com (ARA), bracarense@ufmg.br (AQB)
Resumo: As características de propagação de trinca por fadiga de soldas produzidas em condições convencionais (Soldas feitas fora da agua) e de reparo subaquáticas (Solda subaquática molhada) foram avaliadas fora da agua. As velocidades de crescimento da trinca por fadiga da/dN mostraram uma sensível dependência com a densidade e distribuição de poros, fatores que variam significativamente com o processo de soldagem e meio ambiente. Variações na velocidade de propagação da trinca por fadiga foram correlacionadas com a análise da superfície de fratura na zona de propagação estável da trinca. Os resultados deste estudo mostram que o procedimento de soldagem subaquática molhada produz metal de solda resistente à fadiga que é adequado para uso em baixas tensões aplicadas em estruturas offshore.

Palavras-chave: Propagação da trinca; Fadiga; Soldagem subaquática molhada.

\section{Fatigue Crack Growth Rate in Underwater Wet Welds: Out of Water Evaluation}

\begin{abstract}
Fatigue cracks propagation characteristics of welds produced in conventional conditions (welds made out of water) and underwater condition (Underwater wet welding) were evaluated out of the water. The growth rates of fatigue crack da/dN showed a significant dependency on the density and distribution of pores, factors which may vary significantly with the welding process and environment. Variations in the propagation speed of the fatigue crack were correlated with the analysis of the fracture surface on the stable propagation crack zone. The results of this study showed that the underwater wet welding procedure produces weld metal resistant to fatigue that is suitable to be used at low stresses applied to offshore structures.
\end{abstract}

Key-words: Crack growth; Fatigue; Underwater wet welding.

\section{Introdução}

A escassez das reservas mundiais de petróleo levou as companhias petroquímicas a recorrer, com mais intensidade, a exploração marítima de petróleo (offshore). Como resultado dessa expansão nos últimos anos, o interesse pela soldagem subaquática tem crescido já que este processo é muito utilizado no reparo de instalações offshore, principalmente no Golfo do México. A soldagem subaquática molhada pela sua simplicidade é o processo de soldagem subaquática mais econômico, no entanto as propriedades mecânicas são inferiores as obtidas com processo de soldagem subaquática a seco.

Dados sobre propriedades mecânicas de soldas subaquáticas molhadas ainda são limitados até hoje. No entanto, tem sido reconhecido que a soldagem subaquática molhada com eletrodo revestido têm propriedades mecânicas que são geralmente inferiores às de soldagens de superfície feito em ar [1-3]. A norma ANSI/AWS D3.6-99 [4] especifica os testes que devem ser realizados para determinar as propriedades mecânicas para cada tipo de solda subaquática molhada.

De um modo geral, a solda molhada tem propriedades de tração e tenacidade ao impacto Charpy, reduzidas em comparação à soldagem realizada com o mesmo eletrodo, ao ar a seco. Adicionalmente, as descontinuidades das soldas, tais como inclusão de escória, falta de penetração, falta de fusão, trincamento, mordedura e principalmente porosidade, podem ainda ampliar com o aumento da profundidade de soldagem $[5,6]$. 
Acredita-se que a grande responsável pela redução dos valores das propriedades mecânicas na solda molhada seja a porosidade. Liu [7] afirmam que a influência da porosidade no metal de solda é semelhante à que acontece em aços sinterizados onde a porosidade acaba provocando a redução dos limites de escoamento e ruptura, módulo de Young, ductilidade e tenacidade. Os mesmos autores afirmam que os principais fatores que afetam a porosidade do metal de solda são: Profundidade (pressão), tipo de revestimento do eletrodo e estabilidade do arco.

Por outro lado, quanto ao carregamento cíclico, o comportamento das soldas subaquáticas molhadas tem sido pouco estudado. Desta forma, a avaliação do comportamento a fadiga e corrosão-fadiga torna-se de vital importância já que estes fenômenos de degradação estrutural estão presentes em cerca de $80 \%$ das falhas encontradas nas instalações offshore.

A mecânica de fratura linear elástica (MFLE) está sendo aplicada para caracterizar o comportamento a fadiga de aços e suas juntas soldadas aplicados na indústria offshore por meio da curva da/dN - $\Delta K$, que relaciona a velocidade de propagação da trinca por fadiga com o fator cíclico de intensidade de tensão. No caso particular da solda subaquática molhada, a grande heterogeneidade presente na solda faz com que o comportamento da taxa de crescimento da trinca seja diferente das soldas feitas fora da agua [8].

O objetivo deste trabalho é relatar e avaliar o comportamento da velocidade de propagação da trinca por fadiga em soldas feitas em condições subaquáticas molhadas a diferentes profundidades, simulando 10 e 60 metros da coluna de agua. Também caracterizar a superfície de fratura nas diferentes regiões de propagação da trinca no metal de solda.

\section{Materiais e Métodos}

Para simulação das operações de soldagem molhada nas profundidades de 10 e 60 metros foi utilizada uma câmera hiperbárica como mostrado na Figura 1a. As soldas foram realizadas através de um dispositivo mecanizado para soldagem com eletrodos revestidos (Pat. Req. № PJ 001331) mostrado na Figura 1b, em conjunto com uma fonte de soldagem HipER-1 especialmente projetada e construída para soldagem submarina.
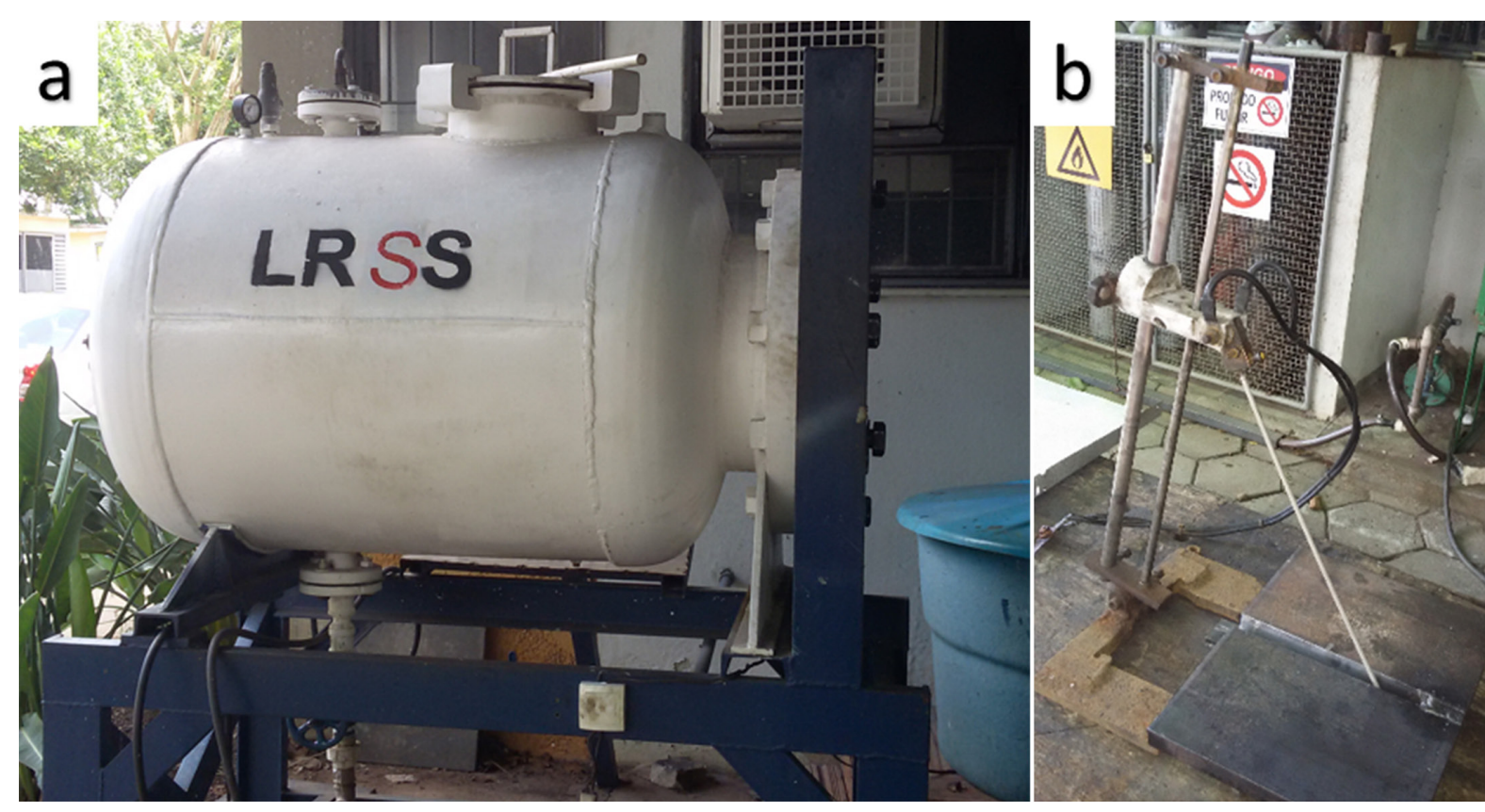

Figura 1. Disposição para soldagem subaquática molhada (a) câmera hiperbárica (b) Sistema de Soldagem por Gravidade. 
Esta fonte tem como tensão de circuito aberto o valor de $75 \mathrm{~V}$ e faixa de corrente para eletrodos revestidos de 30 a 450A. As soldas subaquáticas molhadas foram feitas com eletrodo rutílico $\mathrm{E} 6013 \mathrm{com}$ alma de 3,25mm de diâmetro e $350 \mathrm{~mm}$ de comprimento. Os eletrodos foram protegidos com verniz vinílico Tubolit VVE 815 para evitar a decomposição do revestimento. Foram realizados, em média 16 passes para preenchimento do chanfro e os valores de corrente aplicados, velocidade de soldagem e profundidades na qual foi feita a soldagem estão apresentados na Tabela 1.

Tabela 1. Valores de corrente e velocidade de soldagem para cada profundidade.

\begin{tabular}{cccc}
\hline Eletrodo & $\begin{array}{c}\text { Profundidade } \\
\text { (metros da coluna de agua) }\end{array}$ & Corrente de soldagem $(\mathbf{A})$ & $\begin{array}{c}\text { Velocidade de soldagem } \\
\text { (mm/s) }\end{array}$ \\
\multirow{2}{*}{ E6013 } & 10 & 160 & 3,2 \\
& 60 & 170 & 3,5 \\
\hline
\end{tabular}

Os chanfros soldados em diferentes profundidades foram secionados na parte central para o estudo da porosidade e também para as amostras de macro e micrografias. Para medição e quantificação dos poros e medida de aspectos geométricos dos cordões de solda foi utilizado o programa de tratamento de imagens chamado ImageJ.

Os corpos de prova para os ensaios de propagação de trinca por fadiga foram retirados de forma que a entalhe ficasse localizado nas juntas soldadas conforme apresentado na Figura 2. Os corpos de prova utilizados para os ensaios de velocidade de propagação da trinca foram do tipo Compact - Tension $C(T)$ satisfazendo os requisitos da norma ASTM E 647- 15 [9]. Um extensômetro (clip-gage) foi colocado na "boca do corpo de prova" para monitorar o crescimento de trinca usando a técnica de flexibilidade elástica.

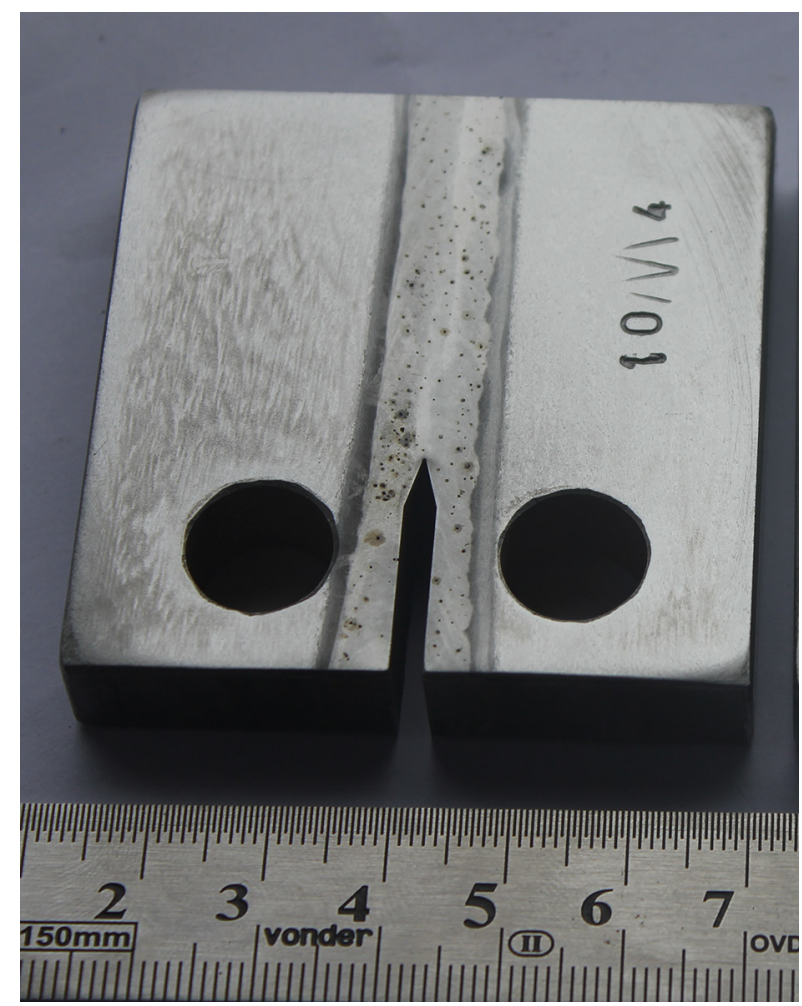

Figura 2. Disposição da solda no corpo de prova C(T) utilizado para o estudo da propagação da trinca por fadiga. 
Os ensaios foram conduzidos em uma máquina servo-hidráulica INSTRON 8802 de 25 toneladas de capacidade. Os testes foram realizados sob controle de carga, mantendo fixa a razão $(R=0,1)$. A onda utilizada no carregamento cíclico foi de tipo senoidal com frequência de $10 \mathrm{~Hz}$. A temperatura durante o ensaio foi de $27^{\circ} \mathrm{C}$ e mantida constante. Os comprimentos de trinca, $a$, foram determinados em relação aos números de ciclos de fadiga, $N$, e as taxas de crescimentos das trincas, $d a / d N$ em função do fator cíclico de intensidade de tensão $\Delta K$, foram determinadas. A taxa de crescimento da trinca por fadiga foi avaliada para determinar expressões generalizadas. A lei de Paris para crescimento da trinca foi considerada, Equação 1.

$$
d a / d N=C(\Delta K)^{m}
$$

A análise da superfície de fratura foi realizada utilizando um microscópio eletrônico de varredura (MEV), situado no Laboratório de Microscopia Eletrônica do CDTN (Centro de Desenvolvimento de Tecnologia Nuclear).

\section{Resultados e Discussão}

$\mathrm{Na}$ Figura 3 mostra-se macrografia de soldas subaquáticas molhadas feitas nas profundidades de 10 e 60 metros da coluna de agua, respectivamente. Pode-se observar o fato relatado na literatura $[1,5]$, onde com aumento da pressão hidrostática na soldagem subaquática molhada aumenta a quantidade de poros no metal de solda.
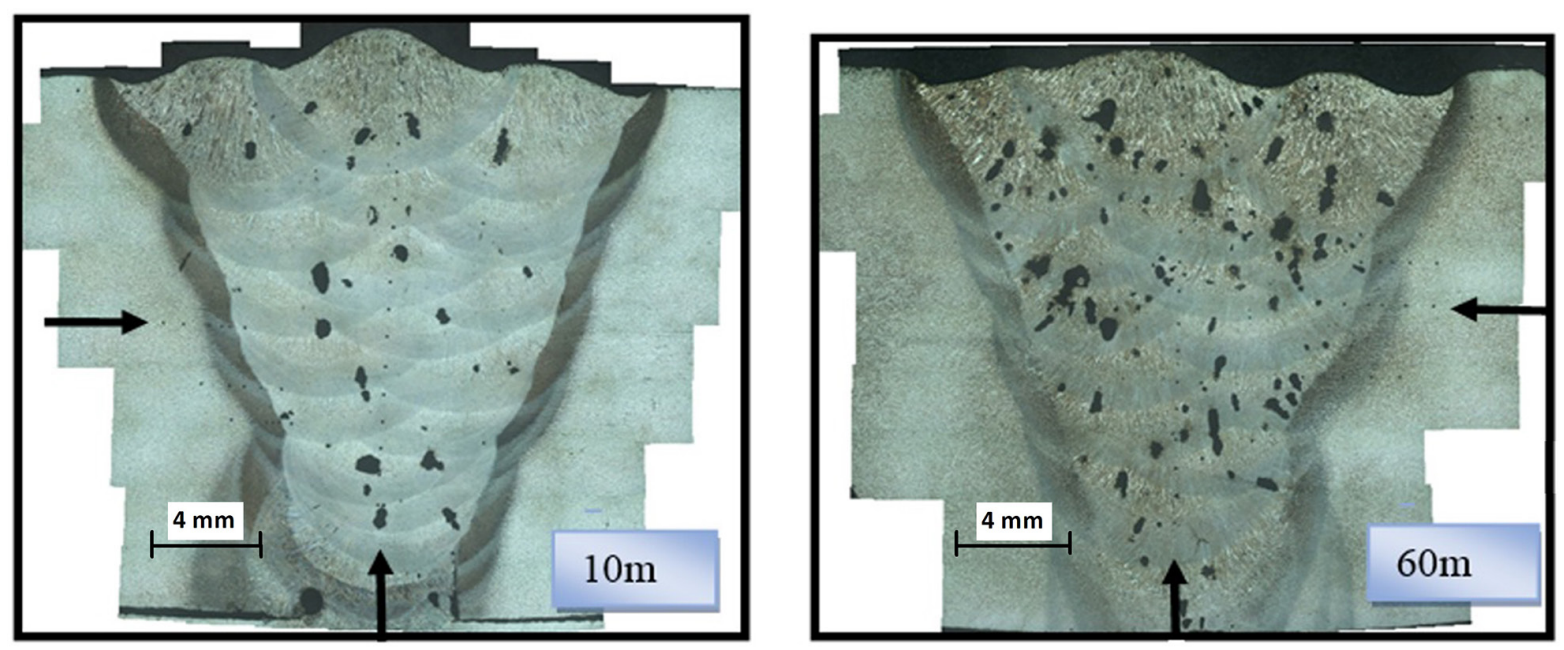

Figura 3. Macrografias de soldas subaquáticas molhadas feitas a 10 e 60 metros de profundidades. As setas indicam as direções das medições de dureza.

Foram realizados ensaios de microdureza nas superfícies das seções transversais das juntas soldadas, testando metal de base, metal de solda e zona termicamente afetada pelo calor. Na Figura 3, as setas mostram o lugar onde foram realizadas as indentações para as medições. Na Tabela 2 apresentam-se os valores médios de dureza com seu desvio padrão, para cada região das soldas subaquáticas molhadas e as feitas no ar. Observou-se que a dureza não muda significativamente com o aumento da profundidade de soldagem de 10 para 60 metros da coluna de agua. Por outro lado, conforme esperado, obteve-se durezas na ZTA superiores a dureza do metal de base nas profundidades de soldagens subaquáticas molhadas testadas.

Na Figura 4 apresenta-se a análise para medir a porosidade por meio do software de processamento de imagem. O primeiro passo é a determinada a área da solda. Depois a área total dos poros. A porcentagem de descontinuidades tipo poro para soldas subaquáticas molhadas é a diferença entre as duas áreas encontradas. Foram achados valores de $2 \%$ para soldas feitas a 10 metros e $6,8 \%$ para soldas feitas a 60 metros. 
Tabela 2. Valores de microdureza de soldas subaquáticas molhadas realizadas a 10 e 60 metros de profundidade e de soldas feitas no ar.

\begin{tabular}{lccc}
\hline & \multicolumn{3}{c}{ Valores médios de microdureza por região (HV) } \\
\cline { 2 - 4 } $\begin{array}{c}\text { Regiões onde foram realizadas as indentações } \\
\text { para o teste de dureza. }\end{array}$ & $\begin{array}{c}\text { Região central do } \\
\text { metal de solda } \\
\text { desde a raiz até o } \\
\text { reforço }\end{array}$ & $\begin{array}{c}\text { Zona termicamente } \\
\text { afetada pelo calor }\end{array}$ & Metal base \\
Solda feita a 10 metros de profundidade & $173,2 \pm 23,4$ & $271,2 \pm 21,2$ & $165,7 \pm 9,1$ \\
Solda feita 60 metros de profundidade & $174,7 \pm 24,6$ & $250,3 \pm 19,8$ & $164,2 \pm 8,5$ \\
Solda feita no ar & $161,2 \pm 12,5$ & $180,2 \pm 15,5$ & $160,9 \pm 9,2$ \\
\hline
\end{tabular}
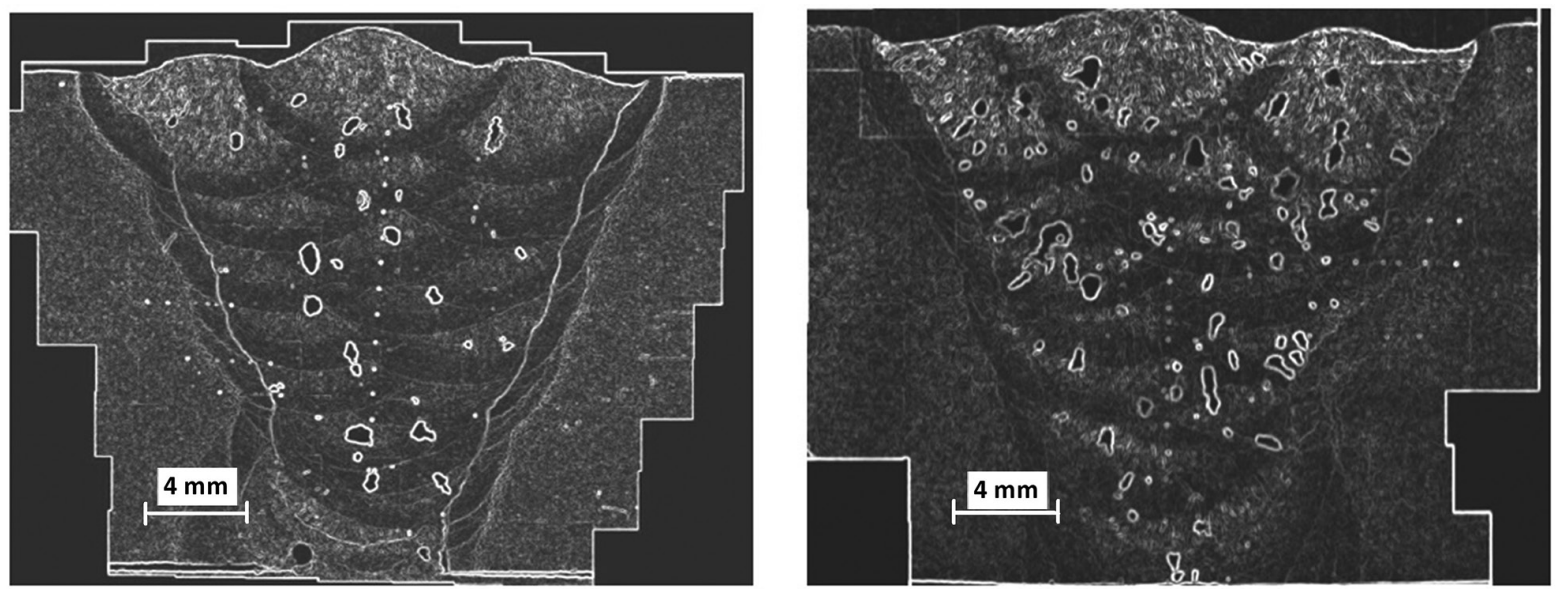

Figura 4. Imagem (mozaico) utilizada para determinação da porcentagem de poro em soldas subaquáticas molhadas feitas a 10 e 60 metros de profundidade.

Na Figura 5 apresenta-se os resultados do teste de velocidade de propagação da trinca por fadiga (da/dN) versus fator de intensidade de tensões $(\Delta K)$ de soldas feitas em diferentes condições: ao ar, na pressão atmosférica, e subaquática molhada, a 10 e 60 metros da coluna de agua.

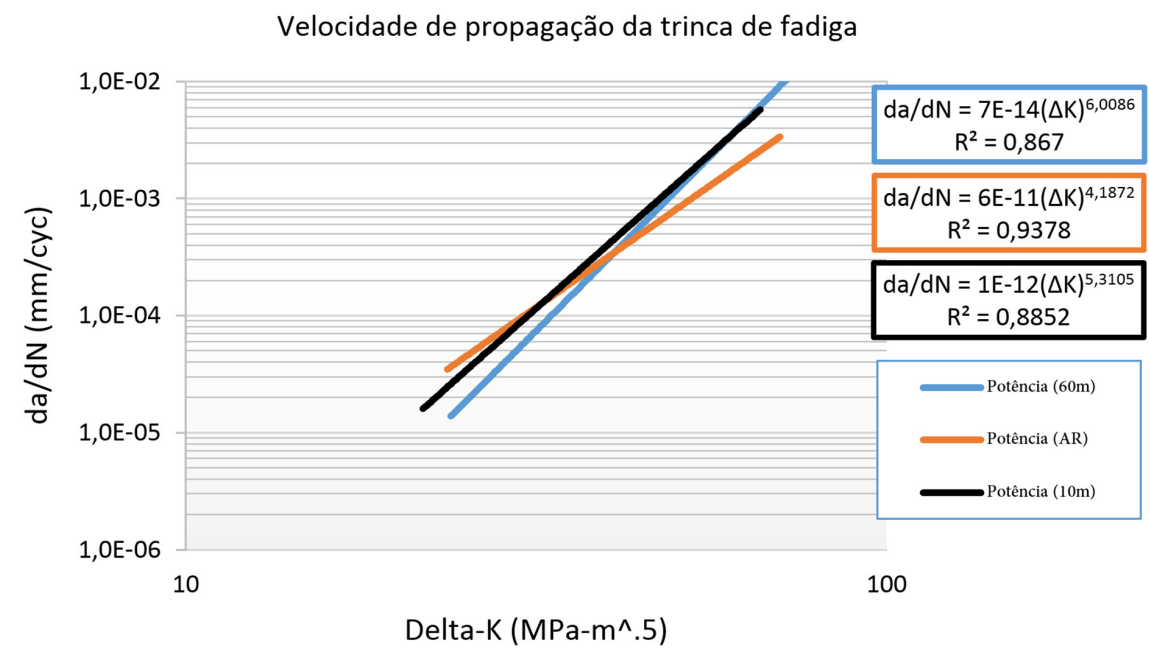

Figura 5. Curvas de taxas de propagação da trinca por fadiga (da/dN) vs fator de intensidade de tensões ( $\Delta K$ ) de soldas feitas ao ar e subaquáticas molhadas em profundidades de 10 e 60 metros. 
Os resultados indicam de forma geral que as soldas realizadas em condições subaquáticas molhada têm uma menor resistência à propagação da trinca por fadiga que as soldas feitas em condições atmosféricas. Este fato está provavelmente associado à quantidade de descontinuidades presentes, como apresentado na Figura 6 de uma solda feita a 60 metros de profundidade. Nesta figura pode-se ver ainda a possível região a ser atingida pela trinca de fadiga. Fatores como as diferenças microestruturais, produto dos multipasses, trincas de hidrogênio perpendiculares ao sentido de propagação da trinca gerada no teste, quantidade e orientação dos poros e diferentes propriedades mecânicas na zona de singularidade, fazem com que velocidade de propagação da trinca por fadiga em soldas subaquáticas molhadas tenha uma maior dispersão nos resultados, como mostra os valores de $R^{2}, 0,867$ para a solda feita a 60 metros de profundidade, 0,8852 para solda feita a 10 metros profundidade $e$ 0,9378 para solda feita ao ar, na Figura 5.

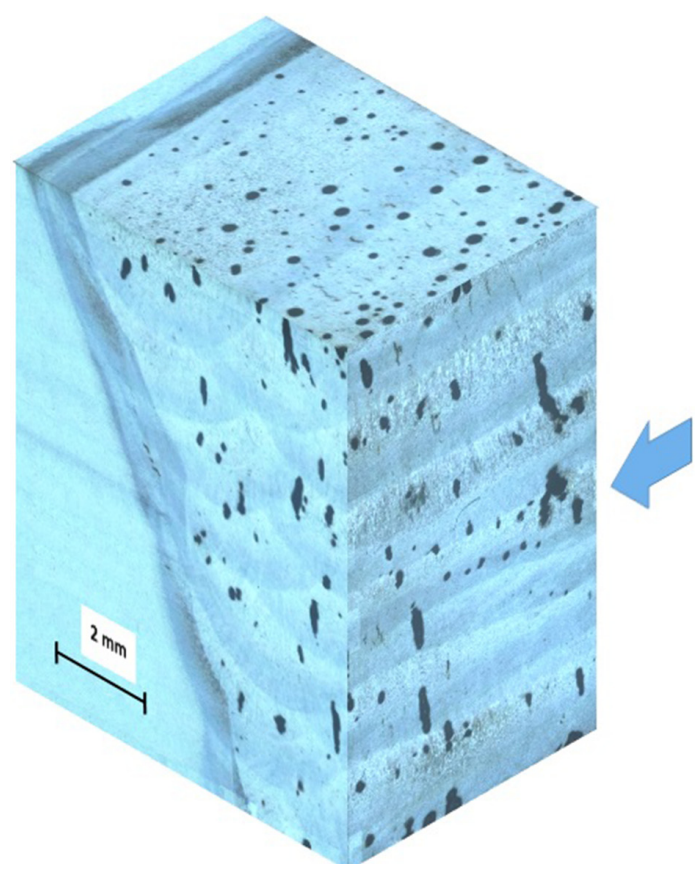

Figura 6. Isométrico da solda subaquática molhada feita 60 metros de profundidade. A seta sinaliza a face onde a trinca por fadiga deve passar.

Os resultados apresentados na Figura 5 revelam ainda que para valores baixos de $\Delta \mathrm{K}$ a velocidade de propagação da trinca para soldas subaquáticas molhadas é menor, ou seja, a resistência à fadiga é maior, o que sugere que os poros são ancoradores da frente da trinca, retardando a taxa de propagação desta trinca por fadiga com baixo fator de intensidade de tensão aplicada.

Na Figura 7 apresenta-se a superfície de fratura de corpos de prova C(T) que contem soldas feitas ao ar, a 10 metros e a 60 metros de profundidade. Nota-se que zona de propagação estável da trinca é ligeiramente menor nas soldas realizadas em condições subaquáticas. Este fenômeno pode estar motivado pela perda da área resistiva por causa da porosidade.

Na Figura 8 apresenta-se um mosaico de imagens geradas no MEV da região de propagação estável da trinca por fadiga de uma solda subaquática molhada feita a 60 metros de profundidade. Na figura pode-se notar que para baixos níveis de $\Delta K$ (pequenos comprimento da trinca) a quantidade de poros atingido pela frente da trinca é menor que quando existem altos níveis de $\Delta K$. Este fato sugere que a trajetória da trinca por fadiga para baixos níveis de $\Delta K$ mantem-se mais reta, ou seja, procurando manter o Modo I de carregamento. À medida que vai aumentando os níveis de $\Delta \mathrm{K}$ (aumentando o comprimento da trinca) a trinca procura poros vizinhos ou pequenas trincas nucleadas nesses poros vizinhos, colapsando e favorecendo a sua propagação. Este fato faz com que o caminho caraterístico da trinca no Modo I de carregamento seja alterado, provocando uma superfície de fratura mais irregular, expondo assim uma maior quantidade de poros. 


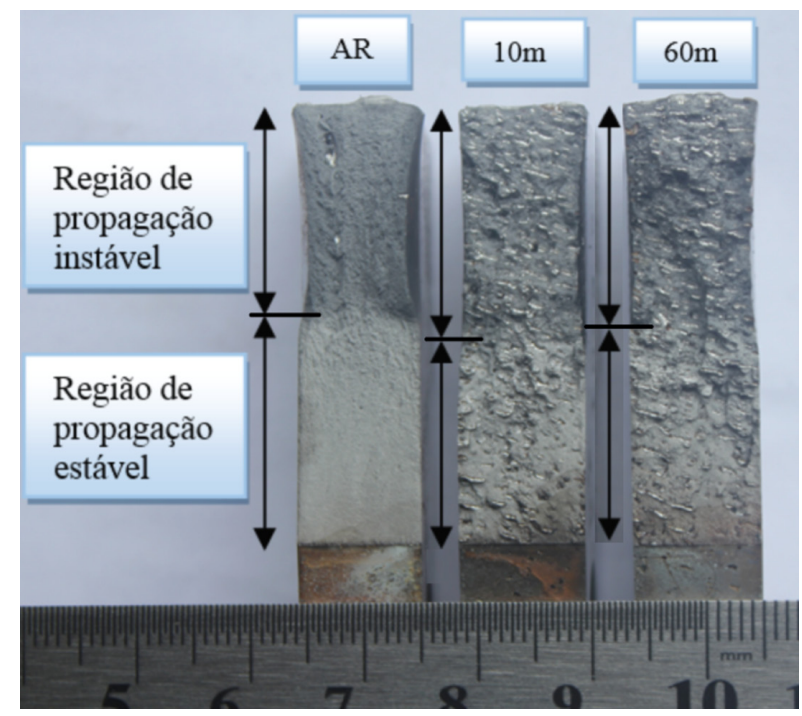

Figura 7. Superfície de fratura de CPs com soldas feitas ao ar e subaquática molhada realizadas a 10 e 60 metros de profundidade.

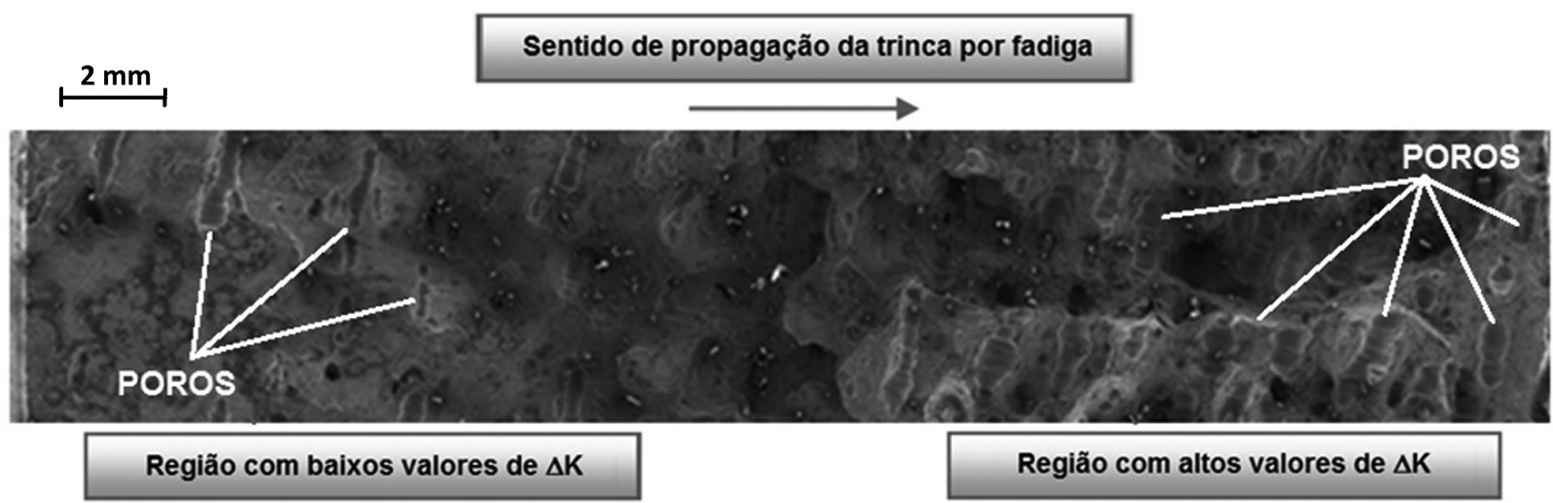

Figura 8. Imagem realizada com MEV da superfície de fratura da região de propagação estável da trinca por fadiga de uma solda subaquática molhada feita a $60 \mathrm{~m}$ de profundidade.

Contrariamente ao que foi encontrado, na literatura [10] é relatado que a deflexão da trinca gera diminuição da taxa de crescimento em materiais contínuos. Como em solda subaquática molhada encontra-se uma elevada quantidade de poro, tem-se que este material não é continuo. Portanto, é possível então que a velocidade de propagação da trinca no modo misto I e II no material remanescente provocada pela deflexão da trinca entre dois poros possa ser menor que a taxa de propagação somente no modo I (sem deflexão). Entretanto, o fato de se ter muitos espaços vazios, porosidade, torna o somatório da velocidade geral de propagação da trinca por fadiga maior, podendo explicar o aumento da velocidade de propagação da trinca, mesmo com um caminho mais tortuoso. Para exemplificar, apresenta-se a Figura 9 onde pode-se notar um aumento na deflexão da trajetória da trinca do corpo de prova com solda subaquática molhada em comparação com o corpo de prova da solda feita ao ar.

Na Figura 10 apresenta-se a imagem da superfície de fratura de dois corpos de prova com soldas subaquáticas molhadas feitas a 10 metros de profundidade. No primeiro CP, marcado como 103, foi realizado o teste de fadiga utilizando a técnica de $\Delta K$ decrescente onde os valores de carregamento cíclico vão diminuindo e consequentemente diminuindo os valores de $\Delta K$. Nota-se que a topografia gerada pela trajetória da trinca de fadiga é bem uniforme, quando comparada com a imagem ao lado do CP marcado com 105, onde o teste de fadiga foi realizado mantendo a carga constante. Neste caso o valor de $\Delta \mathrm{K}$ aumenta com o incremento do comprimento da trinca. 

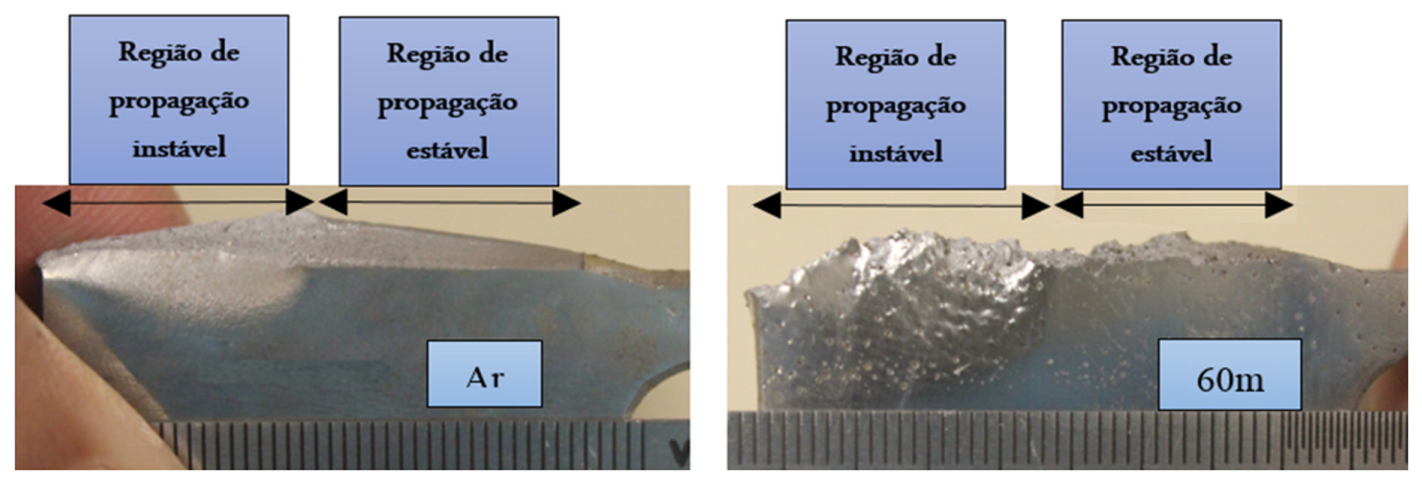

Figura 9. Superfícies de fratura de CPs com soldas feitas dentro e fora da água.

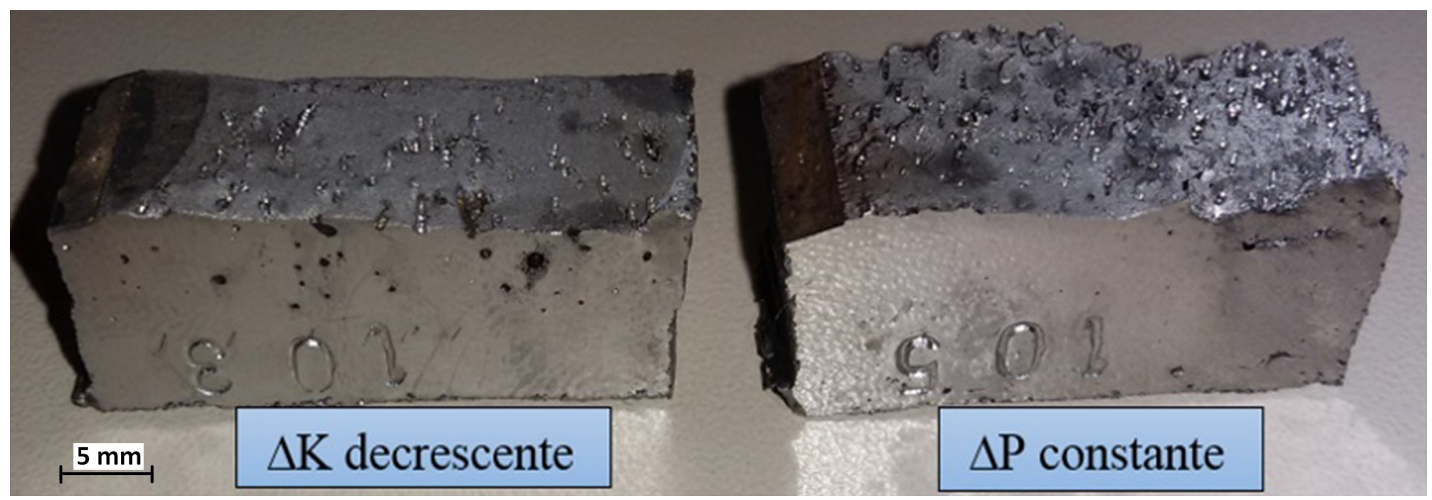

Figura 10. Superfícies de fratura de CPs com soldas subaquáticas molhadas testadas a fadiga com as técnicas de $\Delta \mathrm{K}$ decrescente e $\Delta \mathrm{P}$ constante.

Sabe-se que existe degradação das propriedades mecânicas do cordão da solda subaquática molhada quando comparado com soldas feitas ao ar [8]. A redução das propriedades de tração chega a $20 \%$ enquanto a redução da ductilidade a 50\%. A Figura 11 apresenta um corte da seção transversal do início da zona de propagação instável da trinca da solda feita a 60 metros de profundidade e da feita ao ar, onde é possível ver claramente a diferença na redução de área, o que provoca redução na ductilidade. A figura ainda apresenta que, no caso da solda feita
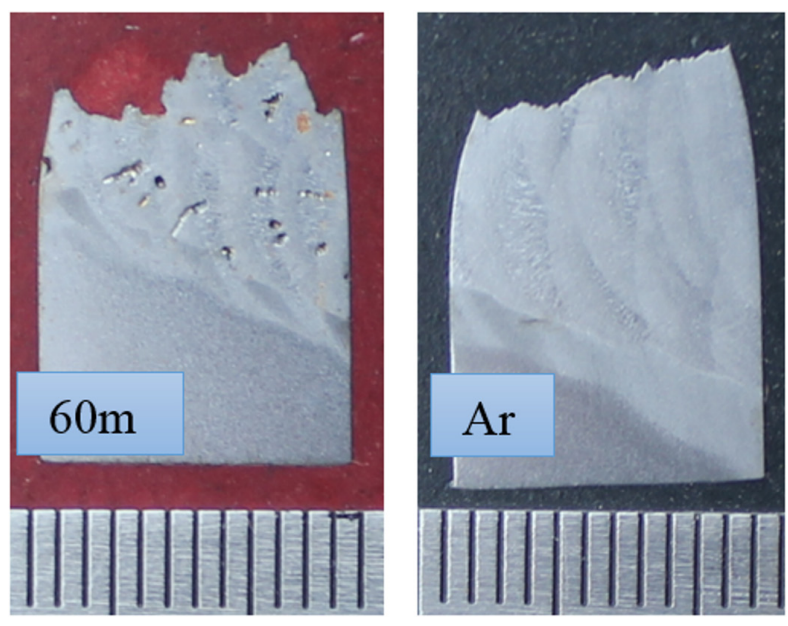

Figura 11. Macrografia no sentido da espessura do CP de solda subaquática molhada feita 60 metros e solda feita ao ar, mostrando na parte superior o perfil da superfície de fratura na região de propagação instável. 
ao ar, livre de defeitos, a fratura ocorre num ângulo de aproximadamente $45^{\circ}$ em relação ao carregamento, demostrando que foi atingido o estado plano de tensões e o comportamento dúctil do material. No caso da fratura na solda subaquática molhada feita a 60 metros, quando atingido o estado plano de tensões, não se observa um ângulo caraterístico deste estado. Neste material ocorre uma coalescência dos poros e deformações plásticas nas regiões remanescentes entrem os poros, provocando aleatoriedade no plano de fratura esperado corroborando com os resultados apresentados.

\section{Conclusões}

A partir da avaliação da velocidade de propagação da trinca de fadiga em soldas realizadas em condições subaquática molhada, as seguintes conclusões foram obtidas:

- Não foram encontradas variações significativas da dureza nas possíveis regiões de propagação da trinca de fadiga nos metais de soldas subaquáticas molhadas realizadas a 10 e 60 metro de profundidade.

- Constatou-se que existe uma grande heterogeneidade nas soldas multipasses realizadas em condições subaquática molhada (trincas hidrogênio, poros com tamanhos diferentes, mudança de propriedades mecânicas na zona de singularidade, etc.) fazendo com que os testes de velocidade de propagação da trinca por fadiga nestas soldas tenham uma maior dispersão nos resultados como mostra o fator $\mathrm{R}^{2}$.

- Os resultados dos ensaios de taxa de propagação da trinca por fadiga mostraram que para soldas com maiores níveis de descontinuidades (porosidade) o expoente $m$ da expressão de Paris aumenta. Com isto, de forma geral, a resistência à fadiga das soldas é menor, apesar de, para níveis baixos de $\Delta \mathrm{K}$ apresentarem um retardo da propagação da trinca (maior resistência à fadiga) e para altos níveis de $\Delta \mathrm{K}$ uma aceleração da trinca (menor resistência à fadiga).

- Nas superfícies de fratura de soldas com alto nível de porosidade constatou-se uma mudança na trajetória da trinca com relação aos níveis de $\Delta K$ explicando a variação de resistência à fadiga ao longo da propagação estável da trinca.

- A coalescência dos poros provoca um aumento na velocidade de propagação da trinca por fadiga na região de propagação estável.

\section{Agradecimentos}

Os autores agradecem ao LRSS (Laboratório de Robótica, Soldagem e Simulação) da UFMG pela oportunidade de desenvolver este trabalho, além de fornecer insumos e materiais necessários para o mesmo. Os autores também agradecem ao CNPq - Conselho Nacional de Desenvolvimento Científico e Tecnológico e a CAPES - Coordenação de Aperfeiçoamento de Pessoal de Nível Superior pelo suporte financeiro a este trabalho.

\section{Referências}

[1] Rowe M, Liu S. Recent developments in underwater wet welding. Science and Technology of Welding and Joining. 2001;6(6):387396. http://dx.doi.org/10.1179/stw.2001.6.6.387.

[2] Di Lorenzo R, Soares W, Bracarense A. Fracture toughness of ferritic steel-underwater wet welded. SMiRT. 2005;18:18821895.

[3] Musumoto I, Kondo A, Nakashima Y, Matsuda K. Study on the underwater welding (Report 2). Journal of the Japan Welding Society. 1971;40(8):748-754. http://dx.doi.org/10.2207/ qjjws1943.40.748.

[4] American Welding Society. ANSI/AWS D3.6M:1999: Specification for underwater welding. Miami: AWS; 1999.

[5] Pessoa ECP, Bracarense AQ, Zica EM, Liu S, Perez-Guerrero F. Porosity variation along multipass underwater wet welds and its influence on mechanical properties. Journal of Materials Processing Technology. 2006;179(1-3):239-243. http://dx.doi. org/10.1016/j.jmatprotec.2006.03.071.
[6] McHenry HI, Potter JM. Fatigue and fracture testing of weldments. West Conshohocken: ASTM International; 2013.

[7] Liu S, Pope AM, Daemen R. Welding consumables and weldability. In: International Workshop on Underwater Welding of Marine Structures; 1994 Dec 7-9; New Orleans. New Orleans; 1994. p. 321-350.

[8] Matlock DK, Edwards GR, Olson DL, Ibarra S. Effect of sea water on the fatigue crack propagation characteristics of welds for offshore structures. Journal of Materials Engineering. 1987;9(1):25-34. http://dx.doi.org/10.1007/BF02833784.

[9] American Society for Testing and Materials. ASTM E647-15: Standard test method for measurement of fatigue crack growth rates. West Conshohocken: ASTM International; 2015.

[10] Suresh S. Crack deflection: Implications for the growth of long and short fatigue cracks. Metallurgical Transactions. A, Physical Metallurgy and Materials Science. 1983;14(11):2375-2385. http://dx.doi.org/10.1007/BF02663313. 